\title{
Ultrastructure of plant cells
}

\author{
Andreas Holzinger ${ }^{1}$ (D) \\ Published online: 30 September 2021 \\ (c) The Author(s), under exclusive licence to Springer-Verlag GmbH Austria, part of Springer Nature 2021
}

This issue 'Ultrastructure of Plant Cells' is dedicated to the memory of the late Prof. Ursula Lütz-Meindl, University of Salzburg who sadly passed away on May 14th, 2020. Her vita and achievements are described in a previous editorial in Protoplasma (Holzinger 2020) and as it was stated thereher spirit to look for scientific truth lives on. The slightest detail in the ultrastructure may be necessary to understand a cell's function-a concept Ursula Lütz-Meindl has followed successfully for four decades. It was my honor to assemble a series of 14 publications in the wider context of plant ultrastructure and how these features influence multiple capabilities, defense reactions and functions. The issue brings together several topics related to ultrastructural research in plant cells deriving from a wide phylogenetic background. In three of the publications Ursula Lütz-Meindl serves as a post-humous author, as she contributed substantially to these studies during her lifetime.

The first study by Steiner et al. (2021), her last PhD student brings new aspects on freezing stress in Ursula's favorite research object, Micrasterias denticulata. Starting with extensive climate data from the natural habitat at Überling-Alm, Salzburg, Austria, the tolerance of this alga to frost and winter scenarios was tested down to the resolution of a TEM after a sophisticated procedure with monitored freezing, CRYO-transfer and high-pressure freeze fixation, and these data were compared with Micrasterias cells fixed in situ at the onset of winter. Overall, this alga cannot be hardened and overwinters usually protected by snow cover. In the next study, Micrasterias was investigated by means of confocal RAMAN spectroscopy (Fig. 1, see also cover illustration of this issue). Felhofer et al. (2021) nicely illustrate the cellular components and most interestingly differences in cellulose deposition in the young semi cells with

Handling Editor: Peter Nick.

Andreas Holzinger

Andreas.Holzinger@uibk.ac.at

1 Department of Botany, University of Innsbruck, Sternwartestrasse 15, 6020 Innsbruck, Austria a possible implication for cell shape formation. Again, this research was started by Ursula Lütz-Meindl in collaboration with Notburga Gierlinger from the University of Natural Resource and Life Sciences in Vienna, but fate did not allow the completion of this study during her lifetime. In a third study with the contribution of Ursula Lütz-Meindl an uncommon red alga was analyzed, Tsunamia transpacifica growing on plastic drift that was found ashore in Oregon, USA, deriving from the 2011 Tsunami in Japan. Holzinger et al. (2021) have summarized some of the astonishing ultrastructural features, EELS measurements of cobalt, phosphorus and iron, as well as the low molecular weight carbohydrate composition of this organism. These findings illustrate how nature can deal with man-made pollution, and that it even can be used as new habitat for organisms, that have not even been detected before.

The sexual reproduction of the streptophytic green alga Mougeotia spp. is highlighted by Permann et al. (2021), who give a comprehensive overview of the composition of the zygospore walls, as well as the remodeling of cell walls during the conjugation process. Again, confocal RAMAN spectroscopy allowed the authors to detect the chemical composition of the zygospore walls, which contained sporopollenin-like aromatic compounds, usually known only from pollen grains. In another Zygnematopyte, Penium margaritaceum a detailed study on osmotic stress and the ultrastructural consequences, has been carried out by Domozych et al. (2021). A shift in cell wall composition of the outer homogalacturonan-rich layer was observed, going along with morphological changes and the formation of a 'filamentous' phenotype. Green algae of the chlorophytic lineage were investigated by Medwed et al. (2021), who give a broad ecophysiological description of Diplosphaera chodatii, an alga that shows desiccation tolerance at its natural tree bark habitat. An uncommon bi-layered cell wall architecture is illustrated in images of the ultrastructure after high-pressure freeze fixation/freeze substitution performed in Ursula Lütz-Meindl's laboratory. In another study of algal reaction to cold and dark environments, Hejduková and Nedbalová (2021) investigated 12 strains of benthic non-marine pennate 


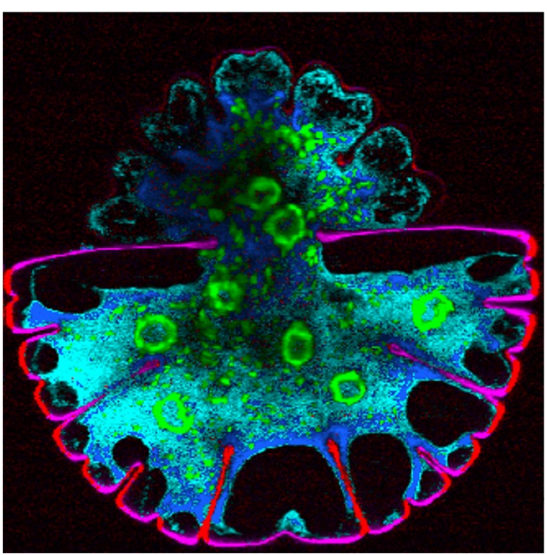

Fig. 1 Confocal RAMAN spectroscopy of Micrasterias denticulata. Image: Notburga Gierlinger, for details see cover illustration and Felhofer et al. (2021)

diatoms. No morphologically distinct resting stages were found, yet four of the 12 investigated strains survived freezing in some of the treatments, and an increase in tolerance was observed in nutrient depleted cells.

Besides eukaryotic algae, cyanobacteria are also examined in this issue. Zekri et al. (2021) investigate the alkaliphilic cyanobacterium Limnospria fusiformis from tropical soda lakes and the breakdown of blooms after cyanophage infection. Prophage components were investigated by CLSM, and lysogentic cyanophages were chemically induced by mitomycin C (MCC) treatments, where the ultrastructural consequences were investigated by means of $3 \mathrm{D}$ reconstruction.

Higher plant cell infections by viruses are also the topic of a study comparing the effects of Zucchini yellow mosaic virus and Tobacco mosaic virus in pumpkin and tobacco plants, respectively were investigated by TEM 3D-reconstruction illustrated in the paper by Zechmann et al. (2021). Damage to chloroplasts, mitochondria and the occurrence of VIRAL inclusion bodies could be quantified through the 3D-reconstructions and showed that these two viruses caused different damage symptoms.

As this issue emphasizes plant cells, several publications highlight the structure and function of cell walls and their adhesives (e.g. Holzinger et al. 2021; Felhofer et al. 2021; Domozych et al. 2021; Medwed et al. 2021). Moreover, Driouich et al. (2021) presents in a review article root capderived cells and mucilage as a protective network. A characterization of the root extracellular trap (RET) related to the defensive peptides and proteins of the neutrophil extracellular trap (NET) of mammalians. These RETs are rich in arabinogalactan proteins related to highly glycosylated human mucins. This review brings a nice inter-kingdom bridge of the defensive function of these important cellular components. Xin \& Herburger (2021) give in another review article a comprehensive overview on lignin-, suberinand cutin-precursor biosynthesis. The resulting extracellular matrix with its hydrophobic biopolymers provides not only mechanical strength, but limits water loss and prevents pathogen invasion, and thus is extremely important as a plant surface barrier. Given the importance for plant live and survival it is astonishing that still large gaps in their precursor biosynthesis exist. The pseudometallophyte Rumex acetosella occurs in habitats with high soil concentrations of zinc, lead and copper by Čiamporová et al. (2021). Leaf structure, physiology, and metal contents were analyzed by light and electron microscopy and element localization were performed by X-ray analysis or specific dyes. Several ultrastructural changes, such as fine wall ingrowths, higher contents of $\mathrm{Zn}$ and $\mathrm{Cu}$ in epidermal and glandular cells were detected suggesting structural properties of glandular heads involved in the secretion of toxic metal ions. Lichtscheidl et al. (2021) contributed another interesting study on Drosera capensis a carnivorous plant and a less studied object in cell biology. Gland cells absorb and transport nutrients, a system that was experimentally targeted by offering fluorescent albumin and following its uptake. Several ultrastructural peculiarities were observed after high-pressure freeze fixation followed by freeze substitution. Last, but not least, Winship et al. (2021) present an elegant, more theoretical work on the correlation of the pollen tube curvature and the growth oscillations in this highly specialized model system on tip growth.

Overall, this issue contains many topics in plant cell biology, and brings together a cohort of authors that had either direct contact with Ursula Lütz-Meindl as a collaborator or were inspired by her work by methodological aspects of high-pressure freeze fixation and 3-D reconstruction, which revolutionized transmission electron microscopy. Many of her research topics are still under investigation, hopefully several of the started studies will be finished by her collaborators. This issue can only be a small glimpse on cell biological questions that were interesting to Ursula LützMeindl. I think I can speak in the name of the 85 authors contributing to the issue-Ursula you all inspired us and we miss you!

One last word should be said by a former student, Prof. Elisabeth Ehler, Kings College, London, who commented on the 'role model', that Ursula had been for her own life and career. 'When I heard about Ursula Lütz-Meindl's passing my thoughts went back to my student days and it suddenly struck me, how much of a role model she had been to me! Coming from a traditional Austrian background, for me the fact that there was a female (!), who was a lecturer at University (!) and extremely competent at it, too (!), (and somewhat snazzily dressed!), was a completely novel experience andas I realize now more than 33 years later-unconsciously instilled in me the thought-well, you could do that, too. 
So, a way too belated thank you and regrets that this didn't happen in time'.

Acknowledgements The author wants to thank Prof. Emeritus Peter $\mathrm{K}$. Hepler for support during editing this special issue, for critically reading this editorial and for a long-time friendship since his stay in the 'Hepler-laboratory' nearly 30 years ago. The work was supported by FWF project P34181-B to AH.

\section{References}

Čiamporová M, Nadubinská M, Banásová V, Durisová V, Zelinová V, Horak O, Gruber D, Lichtscheidl IK (2021) Structural traits of leaf epidermis correspond to metal tolerance in Rumex acetosella populations growing on metal-contaminated soils. Protoplasma. https://doi.org/10.1007/s00709-021-01661-x

Domozych DS, Kozel L, Palacio-Lopez K (2021) The effects of osmotic stress on the cell wall-plasma membrane domains of the unicellular streptophyte, Penium margaritaceum. Protoplasma. https://doi.org/10.1007/s00709-021-01644-y

Driouich A, Gaudry A, Pawlak B, Moore JP (2021) Root cap-derived cells and mucilage: a protective network at the root tip. Protoplasma. https://doi.org/10.1007/s00709-021-01660-y

Felhofer M, Mayr K, Lütz-Meindl U, Gierlinger N (2021) Raman imaging of Micrasterias: new insights into shape formation. https://doi. org/10.1007/s00709-021-01685-3

Hejduková E, Nedbalová L (2021) Experimental freezing of freshwater pennate diatoms from polar habitats. Protoplasma. https://doi.org/ 10.1007/s00709-021-01648-8

Holzinger A (2020) Ursula Lütz-Meindl (1956-2020): a devoted plant cell biologist. Protoplasma 257:1017-1018. https://doi.org/10. 1007/s00709-020-01525-w

Holzinger A, Obwegeser S, Andosch A, Karsten U, Oppermann C, Ruth W, van de Meene A, Goodman CD, Lütz-Meindl U, West JA (2021) The red alga Tsunamia transpacifica (Stylonematophyceae) from plastic drift shows adaptation to its uncommon habitat in ultrastructure and soluble low molecular weight carbohydrate composition. Protoplasma. https://doi.org/10.1007/ s00709-021-01674-6

Lichtscheidl I, Lancelle S, Weidinger M, Adlassnig W, Koller-Peroutka M, Bauer S, Krammer S, Hepler PK (2021) Gland cell responses to feeding in Drosera capensis, a carnivorous plant. Protoplasma. https://doi.org/10.1007/s00709-021-01667-5

Medwed C, Holzinger A, Hofer S, Michalik D, Glaser K, Karsten U (2021) Ecophysiological, morphological, and biochemical traits of free-living Diplosphaera chodatii (Trebouxiophyceae) reveal adaptation to harsh environmental conditions. Protoplasma. https://doi.org/10.1007/s00709-021-01620-6

Permann C, Herburger K, Niedermeier M, Felhofer M, Gierlinger N, Holzinger A (2021) Cell wall characteristics during sexual reproduction of Mougeotia sp. (Zygnematophyceae) revealed by electron microscopy, glycan microarrays and RAMAN spectroscopy. Protoplasma. https://doi.org/10.1007/s00709-021-01659-5

Steiner P, Buchner O, Andosch A, Holzinger A, Lütz-Meindl U, Neuner G (2021) Winter survival of the unicellular green alga Micrasterias denticulata: Insights from field monitoring and simulation experiments. Protoplasma. https://doi.org/10.1007/ s00709-021-01682-6

Winship LJ, Rosen GA, Hepler PK (2021) Apical pollen wall curvature correlates with growth and indicates changes in local viscosity. Protoplasma. https://doi.org/10.1007/s00709-021-01694-2

Xin A, Herburger K (2021) Precursor biosynthesis regulation of lignin, suberin and cutin. Protoplasma. https://doi.org/10.1007/ s00709-021-01676-4

Zechmann B, Müller M, Möstl S, Zellnig G (2021) Three-dimensional quantitative imaging of Tobacco mosaic virus and Zucchini yellow mosaic virus induced ultrastructural changes. Protoplasma. https://doi.org/10.1007/s00709-021-01626-0

Zekri MA, Schagerl M, Schweichhart J, Lang I (2021) Confocal microscopy reveals alterations of thylakoids in Limnospira fusiformis during prophage induction. Protoplasma. https://doi.org/ 10.1007/s00709-021-01656-8

Publisher's note Springer Nature remains neutral with regard to jurisdictional claims in published maps and institutional affiliations. 